\title{
“O QUE QUE ELA QUER SABER DA MINHA VIDA?”: LIMITES E POSSIBILIDADES PARA O SUJEITO NO ENSINO DE LÍNGUA PORTUGUESA POR MEIO DOS GÊNEROS
}

\author{
"¿QUÉ QUIERE ELLA SABER DE MI VIDA?": LÍMITES Y POSIBILIDADES PARA EL SUJETO EN \\ LA ENSEÑANZA DE LA LENGUA PORTUGUESA POR MEDIO DE LOS GÉNEROS
}
"WHAT DOES SHE WANT TO KNOW ABOUT MY LIFE?": LIMITS AND POSSIBILITIES FOR THE SUBJECT IN THE TEACHING OF PORTUGUESE THROUGH GENRES

\author{
Sílvia Letícia Matievicz Pereira \\ Universidade Estadual de Campinas ${ }^{1}$ \\ Terezinha Conceição da Costa-Hübes \\ Universidade Estadual do Oeste do Paraná ${ }^{2}$
}

\begin{abstract}
RESUMO: O objetivo deste trabalho é tecer algumas reflexões sobre uma das implicações da entrada das teorias dos gêneros, especificamente a dos gêneros do discurso (BAKHTIN, 1988; 2003; 2004), como referenciais para o ensino das práticas de linguagem na escola. Interessa-nos refletir sobre o espaço que o ensino de línguas concebe à manifestação e à ampliação da subjetividade do sujeito quando informado por essa orientação teórica. A partir da perspectiva de sujeito em Bakhtin (2003, 2004), analisamos o relato oral de uma estudante do $4^{\circ}$ ano do ensino fundamental, em situação de interação com sua mãe, a respeito de atividades escritas que lhe foram solicitadas pela escola. Trata-se de um corpus gerado em ambiente familiar no ano de 2014, registrado (em áudio) pela própria mãe (pesquisadora em linguagem) e cedido para análise. A partir de análises de base qualitativo-interpretativista são apontados alguns limites e possibilidades para o sujeito no ensino de língua portuguesa por meio dos gêneros.
\end{abstract}

PALAVRAS-CHAVE: gêneros discursivos; ensino de língua materna; sujeito.

RESUMEN: El objetivo de este trabajo es tejer algunas reflexiones sobre una de las implicaciones de la entrada de las teorías de los géneros, específicamente la de los géneros del discurso (BAKHTIN, 1988; 2003; 2004), como referentes para la enseñanza de las prácticas de lenguaje en la escuela. Nos interesa reflexionar sobre el espacio que la enseñanza de las lenguas concibe a la manifestación y a la ampliación de la subjetividad del sujeto cuando es informado por esa orientación teórica. A partir de la perspectiva del sujeto en Bakhtin (2003,2004), analizamos el relato oral de una estudiante de $4^{\circ}$ año de primaria, en situación de internación con su madre, en relación a las actividades escritas que le fueron solicitadas por la escuela. Se trata de un corpus generado en ambiente familiar en 2014, registrado (en audio) por la propia madre (investigadora de lenguaje) y cedido para su análisis. A partir de estos análisis de base cualitativo-interpretativa se apuntan algunos límites y posibilidades para el sujeto en la enseñanza de la lengua portuguesa por medio de los géneros.

PALABRAS CLAVE: géneros discursivos; enseñanza de la lengua materna; sujeto.

ABSTRACT: The purpose of this paper is to present a few thoughts on one of the implications of the entrance of the theories of genres, specifically the one about genres of speech (BAKHTIN, 1988; 2003; 2004), as referential to the teaching of language practices in schools. We are interested in discussing the space given by the language teaching to the subject's manifestation and subjectivity's magnification upon the theoretical orientation. From the subject's perspective in Bakhtin (2003, 2004), we have analyzed the oral report of an elementary school student while interacting with his mother about the written activities that had been given to him by the school - a corpus generated in a family environment in 2014, registered (audio) by the mother herself (a Linguistics researcher) before being transferred for analysis. Based on an interpretative qualitative analysis some limits and possibilities for the subject in Portuguese teaching through genres are pointed out.

KEYWORDS: genres of speech; mother tongue education; subject.

\footnotetext{
${ }^{1}$ Doutoranda em Linguística Aplicada no Instituto de Estudos da Linguagem (UNICAMP), pesquisadora do Grupo Letramento do Professor. Professora Temporária do Curso de Letras da Universidade Estadual do Oeste do Paraná - UNIOESTE, campus de Foz do Iguaçu-Paraná. Contato: sleticiamp@gmail.com

${ }^{2}$ Professora Doutora do Programa de Pós-Graduação Stricto Sensu em Letras - Nível de Mestrado, área de concentração em Linguagem e Sociedade, da Universidade Estadual do Oeste do Paraná - UNIOESTE - Campus de Cascavel-Paraná. Contato: tehubes@gmail.com
} 


\section{INTRODUÇÃO}

A preocupação com o estudo da linguagem para além de uma estrutura imanente é relativamente recente no Brasil e encontra representações em grupos distintos de estudos científicos. De acordo com Travaglia (1996), as áreas de estudo da linguagem que buscam analisá-la em situação de uso, considerando seus aspectos históricos e sociais, podem ser abrigadas sob o rótulo genérico de linguística da enunciação $0^{3}$. Sob essa perspectiva, grosso modo, usamos a língua de acordo a situação comunicativa, com nosso interlocutor, considerando as condições e os contextos histórico e social em que estamos inseridos, o que também inclui os objetivos comunicativos do interlocutor. A linguagem, assim, é o local das relações sociais em que os falantes atuam como sujeitos, os quais agem com e sobre a linguagem, ao mesmo tempo em que sofrem as ações da linguagem (GERALDI, 1997).

Reflexos dessa concepção de linguagem constam nos Parâmetros Curriculares Nacionais (doravante PCN), publicados na segunda metade da década de 90, os quais apontam a abordagem dos gêneros como caminho para o desenvolvimento da capacidade de refletir, de maneira crítica, sobre a língua como instrumento de interação social. Lê-se, nos Parâmetros:

Produzir linguagem significa produzir discursos. Significa dizer alguma coisa para alguém, de uma determinada forma, num determinado contexto histórico. Isso significa que as escolhas feitas ao dizer, ao produzir um discurso, não são aleatórias, mas decorrentes das condições em que esse discurso é realizado. […] O discurso, quando produzido, manifesta-se linguisticamente por meio de textos. Assim, pode-se afirmar que o texto é o produto da atividade discursiva oral ou escrita que forma um todo significativo e acabado, qualquer que seja sua extensão. [...] Todo texto se organiza dentro de um determinado gênero. (BRASIL, 1997, p. 25-26)

É, portanto, a partir do terreno profícuo instaurado pela disseminação, na academia, das teorias da enunciação, assim como da publicação dos PCN, que a discussão sobre dos gêneros adentra os cenários da pesquisa no Brasil (especialmente no escopo da Linguística Aplicada) e do ensino brasileiro. Trata-se da materialização dos gêneros textuais/discursivos como referenciais para 0 ensino das práticas de linguagem na escola e do texto como unidade de trabalho (LUNARDELLI, 2012).

Desse modo, o trabalho com a língua na escola passa a ser considerado como possibilidade de manifestação e ampliação da subjetividade do indivíduo (PERFEITO, 2005). Essa possibilidade consiste em inegável avanço em termos de ensino de língua materna, dado que se passa a considerar a relação da língua com a sociedade e o sujeito, a partir de situações reais de uso.

Tanto esse modo de conceber a linguagem, como a teoria dos gêneros, têm raízes nos estudos do Círculo de Bakhtin", para quem a língua é reflexo das relações dialógicas entre os falantes. Entretanto, é relevante observar que, ao teorizar sobre os gêneros, Bakhtin estava interessado na inter-relação entre a linguagem e a vida social. Não eram preocupações nem do autor nem do Círculo as questões relativas ao ensino de línguas. Por esta razão não há, nas suas obras, o desenvolvimento de proposta(s) de didatização dos gêneros. Assim, ao adentrar a sala de aula via documentos paramétricos de ensino, os gêneros sofrem a transmutação das propriedades de um objeto de estudo para as de um objeto de ensino, hoje compreendido como referenciais para

ensino das práticas de linguagem.

Obviamente, há muitas implicações quando ocorre esse tipo de transmutação. Nesse artigo, pretendemos tecer algumas reflexões sobre uma delas: a compreensão que é possível entrever do lugar do aluno enquanto sujeito da linguagem. Nessa direção, o objetivo principal deste artigo é discutir sobre o papel da entrada dos gêneros como referenciais para o ensino de línguas na escola no que tange à consideração do aluno como sujeito da linguagem, permitindo-lhe (ou não) a manifestação da subjetividade.

\footnotetext{
${ }^{3}$ De acordo com o autor, podem ser abrigadas sob o grande rótulo de teorias da enunciação: a Teoria do Discurso, a Pragmática, a Semântica Argumentativa, a Análise da Conversação, a Análise do Discurso, a Linguística Textual e a Enunciação Dialógica de Bakhtin.

${ }^{4} \mathrm{O}$ Círculo de Bakhtin compreende um grupo de intelectuais de diversas áreas (como filosofia, linguística, literatura, música, etc.) que se reunia regularmente em São Petersburgo, na Rússia, no início do séc. XX para debater questões voltadas especialmente à arte e à filosofia. Além de Bakhtin, compunham o grupo Pavel Medvedev, Valentin Volochinov e outros.
} 
Para atingir esse objetivo, analisamos o relato de uma estudante do $4^{\circ}$ ano do ensino fundamental, da rede privada de ensino de uma escola do oeste paranaense, em duas cenas de interação com sua mãe, referentes a atividades escritas que lhe foram solicitadas pela escola. As cenas foram gravadas (em áudio) pela mãe em 2014 (pesquisadora da área da linguagem) que concedeu esse corpus para análise. Para atender aos propósitos de pesquisa, desenvolvemos uma análise qualitativa, de base interpretativista, conforme orientações de Bortoni-Ricardo (2008), Erickson (1989) e de Denzin \& Lincoln (2006), circunscrita na área da Linguística Aplicada (MOITA LOPES, 2006). Por tratar-se de um caso específico, a pesquisa se caracteriza, também, como um estudo de caso, conforme postula André (2005).

Consideramos a relevância da voz do sujeito na medida em que, por meio dela, é possível entrever o processo de apropriação dos usos da linguagem escrita e, a partir das indicações que são possíveis por meio desse ponto de vista, entender o lugar que é dado ao aluno, nas práticas escolares analisadas, enquanto sujeito que age com e sobre a linguagem.

$\mathrm{Na}$ perspectiva de atender ao proposto, este artigo encontra-se assim organizado: na próxima seção apresentamos suscintamente alguns princípios da concepção dialógica de linguagem (BAKHTIN, 1988, 2003; BAKHTIN;VOLOCHINOV, 2004) e algumas contribuições dessa noção para compreensão da interação humana via linguagem verbal; na sequência, efetuamos análises do relato da estudante, recorrendo, para isso, ao aporte teórico que embasa nossas reflexões. Encerramos este trabalho com o apontamento de algumas implicações para o ensino de língua portuguesa a partir da entrada da teoria dos gêneros na escola.

\section{CONSTITUIÇÃO DOS SUJEITOS NA TEORIA DIALÓGICA DE BAKHTIN}

Conceber a linguagem a partir da perspectiva dialógica do Círculo de Bakhtin implica considerar a natureza social e constitutiva dos enunciados. A noção dialógica da linguagem é difundida em toda a obra do Círculo; não se trata de um conceito que possa ser recortado de um único trecho. Embora não possa ser circunscrito a uma única citação, pode-se dizer, de acordo com Brait (2007), que o dialogismo é entendido pelo Círculo como constitutivo de qualquer discurso. Ele se refere, ainda segundo a autora, tanto às permanentes relações entre os diversos discursos que constituem uma sociedade, os quais se entrecruzam e se interpenetram de formas diversas, quanto às relações discursivas que se estabelecem pela alteridade.

A alteridade - a relação com o outro por meio da linguagem - é constitutiva do "eu". E é nessa interação que a perspectiva dialógica da linguagem se revela em toda sua integridade. Para o Círculo, é por meio da interação verbal que se produz a linguagem e se constituem os sujeitos. Não há sujeitos sem a interação, pois nos constituímos a partir do outro. A experiência discursiva individual de qualquer pessoa se forma e se desenvolve em uma interação constante e contínua com os enunciados dos outros: “[ [...] eu tomo consciência de mim e me torno eu mesmo unicamente me revelando para o outro, através do outro e com o auxílio do outro" (BAKHTIN, 2003, p. 341).

Embora a noção de alteridade perpasse todas as discussões do grupo, não encontramos em suas obras uma indicação pontual do conceito de sujeito; todavia, entendemos que esses estudiosos defendem um sujeito que é constituído socialmente nas relações que estabelece com o(s) outro(s). Trata-se, assim, de um sujeito ativo, participativo, que interage, que tem voz e poder de decisão. Nesse sentido, a noção de que linguagem e sujeito se implicam mutuamente. O sujeito é, assim, construído na e pela linguagem, logo, emerge da alteridade que, por sua vez, se funda na forma como o Círculo entende a enunciação: como um produto da interação entre sujeitos socialmente organizados, a qual carrega consigo as marcas do embate discursivo (BAKHTIN;VOLOCHINOV, 2004). É nesse prisma que sujeito e enunciação se interceptam: tudo o que pertence à consciência individual, chega a ela através dos outros, das palavras dos outros. Lê-se em Bakhtin:

Nosso discurso, isto é, todos os nossos enunciados (inclusive as obras criadas) é pleno de palavras dos outros, de um grau vário de alteridade ou de assimilabilidade, de um grau vário de aperceptibilidade e de relevância. Essas palavras dos outros trazem consigo sua expressão, o seu tom valorativo que assimilamos, reelaboramos, e reacentuamos. (BAKHTIN, 2003, p. 294-295)

Para o Círculo de Bakhtin, produzimos nosso enunciado sempre em diálogo e em resposta a outros enunciados anteriores, com os quais estabelecemos relações dialógicas, travamos embates:

Toda enunciação, mesmo na forma imobilizada da escrita, é uma resposta a alguma coisa e é 
construída como tal. Não passa de um elo da cadeia dos atos de fala. Toda inscrição prolonga aquelas que a precederam, trava uma polêmica com elas, conta com as reações ativas da compreensão, antecipa-as. (BAKHTIN;VOLOCHINOV, 2004, p. 98).

Por assim se constituir, a enunciação é a projeção de uma posição do sujeito no mundo - de/em algum lugar, em algum momento e para um outro. Isso porque estamos sempre dialogando com outros já ditos e nos posicionamos frente a eles, seja de modo a manifestarmos resistência, ou para reelaborarmos, ou ainda, para os apropriarmos como nossos.

É característico da enunciação, portanto, o caráter responsivo-ativo da compreensão. Ou seja, no processo da comunicação discursiva, os enunciadores desempenham um papel ativo um em relação ao outro: “[...] toda compreensão é prenhe de resposta" (BAKHTIN, 2003, p. 271). Nossa compreensão das palavras do outro é sempre ativa na medida em que gera, invariavelmente, réplicas que, mesmo silenciosas (aquelas que guardamos para nós), são efeito daquelas e, assim, interligam-nas a uma cadeia discursiva: “[ [...] os enunciados são sempre um elo na cadeia discursiva e complexamente organizada de outros enunciados" (BAKHTIN, 2003, p. 272).

A concepção de sujeito para o Círculo de Bakhtin se inscreve, portanto, a partir das relações intersubjetivas que ocorrem em uma dada realidade social. Assim como o sujeito não é autônomo - dono das suas palavras e vontades - não é, tampouco, passivo, inconsciente ou livre em relação à língua. O sujeito é, desse modo, dialógico; é aquele que lida com a palavra alheia de modo ativo e responsivo e que, a partir dela, é constituído e também constitui o outro.

Se não há sujeito sem interação social e a interação pressupõe a enunciação, a qual, por sua vez, envolve sujeitos socialmente posicionados e materializa-se por meio de textos, então pode-se dizer que a essência do texto "[...] sempre se desenvolve na fronteira de duas consciências, de dois sujeitos." (BAKHTIN, 2003, p. 311 , grifos do autor). Sendo assim, os sujeitos se interceptam por meio de gêneros discursivos.

Isso significa que os modos de dizer de cada sujeito têm origem não no seu psiquismo individual, mas são resultado das possibilidades oferecidas pela língua em situações concretas de comunicação, sempre sóciohistoricamente marcadas. E esses modos de dizer só podem concretizar-se por meio dos gêneros discursivos. Os gêneros são, pois, a materialização discursiva do diálogo; a intersecção entre a dimensão individual e social da enunciação.

Para Bakhtin, “[...] os gêneros têm um significado particularmente importante. Ao longo dos séculos, os gêneros (da literatura e do discurso) acumulam formas de visão e assimilação de determinados aspectos do mundo" (BAKHTIN, 2003, p. 364). Logo, os gêneros do discurso são construtos históricos e culturais que carregam em si a linguagem em toda plenitude de vida. Sendo assim, para ensinar a língua viva, dinâmica, socialmente constituída, é preciso recorrer aos gêneros que representam uma diversidade de formas de enunciados, o que os torna importantes para esse contexto de ensino.

Ao abordar os gêneros discursivos como práticas sociais de uso da linguagem, partimos da assunção de que eles não são criados pelos falantes, mas lhe são dados historicamente. Conforme Bakhtin (2003), todo gênero pressupõe uma esfera social como seu princípio organizador, uma vez que as esferas tipificam as situações de interação, estabilizam relativamente os enunciados que nelas circulam, originando gêneros do discurso particulares dessas esferas. Como diz Rodrigues, "[...] cada esfera conhece e aplica os seus próprios gêneros" (RODRIGUES, 2001, p. 70), posto que as características particulares da constituição e do funcionamento dos gêneros do discurso estão vinculadas às especificidades das esferas sociais nas quais estes funcionam, circulam e se organizam.

Assim compreendidos, os gêneros são descritos pelo autor como formas de enunciados que se caracterizam pelo conteúdo temático - domínio de sentido de que se ocupa o gênero; pela construção composicional - o arranjo interno, os modos de organização textual; e pelo estilo - as marcas linguístico-expressivas do gênero e a seleção dos recursos da língua feita pelo enunciador. Esses elementos estão "indissoluvelmente ligados no todo do enunciado" (BAKHTIN, 2003, p. 262). São eles as matrizes sócio-cognitivas e culturais (MATENCIO, 2003), sem as quais não é possível que participemos de qualquer prática social. O domínio dos gêneros figura, assim, como condição para a circulação dos indivíduos pelas várias esferas de atividades humanas. 


\section{APONTAMENTOS SOBRE O TRABALHO COM OS GÊNEROS NO ENSINO DE LÍNGUA MATERNA}

A entrada da teoria dos gêneros no campo do ensino - e, com ela, as subjacentes concepções de língua e de sujeito - é considerada um avanço por muitos estudiosos da linguagem preocupados com o ensino da língua portuguesa no Brasil (KLEIMAN, 2007; MARTINS, 2009a, 2009b; RODRIGUES, 2009; ROJO, 2005).

Dentre os elementos fortalecedores do ensino de língua, pode-se citar a valorização da instabilidade, da maleabilidade e da flexibilidade dos fatos linguísticos, a consideração da relação entre linguagem e sociedade (MARTINS, 2009a), bem como o reconhecimento de que o sujeito se constitui no embate discursivo de sua experiência social via linguagem.

Essas características do viés enunciativo-discursivo, ao informarem o ensino de língua materna, têm muito a contribuir para a formação de usuários da língua mais cientes de sua posição no mundo e com condições de agir socialmente de forma mais crítica e cidadã.

Entretanto, como dissemos, não há nas obras do Círculo qualquer proposta de didatização para a teoria dos gêneros (LUNARDELLI, 2012)5 , o que fez com que ficasse a cargo dos interessados no ensino de línguas a tarefa de elaborar modelos ou princípios didáticos que levassem em conta a teoria dos gêneros.

Para Acosta Pereira e Rodrigues (2009), as propostas nacionais de didatização da teoria dos gêneros são influenciadas até hoje, em menor ou maior grau, por seis tradições de estudos dos gêneros que têm como preocupação central o ensino de língua materna. São elas: sociossemiótica (que busca compreender a configuração contextual e textual dos gêneros na análise das metafunções e sua relação com a Análise Crítica do Discurso), sociorretórica (que objetiva analisar os gêneros textuais como ações sociais), interacionistasociodiscursiva (que descreve as características enunciativo-discursivas dos gêneros e procura selecionar, planejar e projetar conteúdos de ensino/aprendizagem), semiodiscursiva (vinculada à Análise do Discurso que concebe os gêneros como dispositivos de comunicação), sociocognitivista (da Linguística Textual, que compreende os gêneros como inter-relacionados a competências sociais e cognitivas da comunicação) e, finalmente, a dialógica (vertente que defendemos, objetiva compreender a constituição e o funcionamentos dos gêneros a partir de sua relação com a situação social de interação).

De acordo com esses estudos, a principal causa dos problemas da escrita na escola está no falseamento escolar do uso da linguagem. Há a preocupação comum de superar concepções de linguagem que desprezam seu caráter social: “[…] o que se faz necessário é a criação de situações de interação rica, que transcendam a sala de aula e mesmo o espaço escolar propriamente dito, de tal forma que a linguagem possa ser praticada de forma mais próxima de sua dimensão real” (MARTINS, 2009b, paginação irregular). O que está em jogo é a ideia de que a escola deveria criar espaço para que os alunos participem, efetivamente, de práticas sociais letradas (KLEIMAN, 2007; MARTINS, 2009a; 2009b).

Muitos estudos têm mostrado, contudo, algumas incongruências na transmutação sofrida pelos gêneros ao passar de um objeto de estudo para um referencial de ensino da linguagem. Fiorin (2008), por exemplo, aponta que os gêneros têm sido vistos como um conjunto de propriedades formais que devem ser obedecidas quando se produz um texto e argumenta que " $[\ldots]$ sob a aparência de uma revolução no ensino de Português, está-se dentro da mesma perspectiva normativa com que se ensinava a gramática" (FIORIN, 2008, p. 60).

Já Martins (2009a) observa que a constante preocupação escolar com a categorização e a nomeação dos gêneros é incompatível com a proposta do Círculo de Bakhtin, uma vez que não se considera a flexibilidade e a maleabilidade que lhes são característicos. Segundo ela, estamos dando roupagem nova a velhas práticas:

Estamos muito longe da possibilidade de praticar a linguagem, reconhecida como pertencente a certos gêneros do discurso, enquanto atividade genuinamente ancorada em situações de produção, sejam escolares ou não, e, por isso mesmo, sujeita a manipulações, a distorções, a inovações. A tipologia textual aparece de forma relativamente estabilizada e sentimo-nos bem próximos dos tradicionais exercícios de interpretação e de produção de textos de mais de trinta anos atrás, apenas

\footnotetext{
${ }^{5}$ Em 2013 foi publicada em língua portuguesa a obra “Questões de estilística no ensino da língua”, de autoria de Mikhail Bakhtin. O obra trata de questões de ensino de língua a partir das experiências do autor como professor em escola secundária na Rússia. Além de se tratar de obra recente, ainda pouco disseminada na academia e nas escolas, a obra não se propõe a delinear uma proposta de didatização da teoria dos gêneros. Antes, se dedica a tecer reflexões acerca do ensino tradicional de línguas.
} 
com uma roupagem ligeiramente diferente e com a assimilação canhestra de uma nomenclatura mais atualizada. (MARTINS, 2009a, p. 9)

O que parece evidente é que tem havido consideráveis dissonâncias entre a perspectiva dialógica da linguagem e o trabalho com os gêneros na escola.

Rodrigues (2014) também discute essa questão quando questiona como os gêneros entraram na escola e começaram a fazer parte do discurso escolar e da academia, tanto por meio da formação inicial quanto da continuada, bem como através dos materiais didáticos. Em suas reflexões, a autora entende que há uma confusão conceitual sobre o que sejam gêneros, ora sendo tratados como estrutura dos textos (frases, citações, discurso direto e indireto etc.), ora como sequências tipológicas (descrição, narração etc.). Além do mais, "[...] a noção de gêneros muitas vezes se limita à estrutura dos textos ou, então, a dimensão estrutural se sobrepõe aos elementos de interação" (RODRIGUES, 2014, p. 41). E, nesse sentido,

A preocupação reside no rareamento ou apagamento da dimensão social e interativa dos gêneros, elementos constitutivos da noção gêneros, uma vez que só faz sentido falar em gêneros se falarmos em esfera da atividade humana, interação, autoria, projeto de dizer, interlocutor (RODRIGUES, 2014, p. 42).

Essa preocupação da autora é relevante, pois em muitos casos de ensino e trabalho com os gêneros na escola, o que se focaliza é a sua estabilidade (forma e estrutura), e se apaga (ou se minimiza) a relação dialógica que envolve um projeto de dizer, o acontecimento do enunciado e a historicidade dos gêneros. Assim, os gêneros tornam-se apenas "fôrmas para o aluno preencher, nos moldes da redação escolar, ainda que se fale em interlocutores e publicação dos textos dos alunos, pois esses elementos não são constitutivos do texto que o aluno produz" (RODRIGUES, 2014, p. 43).

Considerando o exposto, na sequência, expomos e analisamos o relato de uma estudante do ensino fundamental acerca de atividades escritas que lhe foram solicitadas pela escola. Procuramos observar especialmente alguns reflexos da entrada da teoria dos gêneros no ensino de língua portuguesa no Brasil, sobretudo no que diz respeito à proposição de um ensino que supere o falseamento da linguagem e considere o aluno como sujeito do próprio dizer.

\section{4 “O QUE ELA QUER SABER DA MINHA VIDA?”: O LUGAR DO ALUNO COMO SUJEITO DA LINGUAGEM}

Os dados que trazemos à luz fazem parte de um corpus gerado em um diálogo entre mãe e filha ${ }^{6}$, revelando, assim, a voz de uma estudante do quarto ano do ensino fundamental, da rede particular de ensino do estado do Paraná, acerca do uso da linguagem escrita na escola. As duas cenas transcritas abaixo fazem parte de um único evento familiar em que a filha, de 8 anos, pede a sua mãe que a ajude na tarefa escolar de língua inglesa.

Embora se refira ao ensino de língua estrangeira, a cena $\theta 1$ não foi descartada por duas razões. Primeiramente porque ela constitui o contexto a partir do qual emerge a cena 2 , em que a filha relata à mãe uma experiência de escrita na aula de língua portuguesa, envolvendo o gênero denominado pela aluna de carta. Portanto, não seria possível compreender a cena 2 , sem a cena 1 . A outra razão diz respeito à pertinência das reflexões da criança, presentes na cena $\theta 1$, sobre sua condição de sujeito no uso da linguagem verbal. Os enunciados dessa cena serão analisados, portanto, apenas tendo em vista essas considerações e a dimensão do uso da linguagem verbal, de forma ampla ${ }^{7}$.

A tarefa de escrita, constante no livro didático da disciplina de língua inglesa, consistia, primeiramente, na leitura de um texto na língua estrangeira, classificado pelo livro como sendo um e-mail. Neste texto, Paula, a

\footnotetext{
${ }^{6}$ Com dissemos, os dados foram gentilmente cedidos pela mãe para esta análise. Segundo seu relato, a gravação só foi possível porque ela, também pesquisadora em linguagem, acabara de chegar do campo de sua pesquisa de doutorado e recém transferira as gravações que fizera para outro dispositivo eletrônico, quando a filha adentrou seu escritório pedindo ajuda com a tarefa escolar. Já estando com o gravador em mãos, a mãe decidiu realizar a gravação, o que resultou nas cenas transcritas neste trabalho.

${ }^{7}$ Não faz parte dos objetivos desse trabalho adentrar no terreno das discussões acerca do ensino de língua estrangeira. Desse modo, mesmo que toque em questões que se referem ao ensino dos gêneros, não as analisaremos nesta cena, dados os limites expostos.
} 
suposta autora $^{8}$, apresenta alguns dados pessoais e relata sua rotina diária. Na sequência, solicita-se ao estudante a elaboração de um texto, também em língua estrangeira, em resposta a este e-mail. Não conseguindo realizar a tarefa, a filha pede ajuda à mãe que, após ler as instruções para a atividade escrita, inicia a interação transcrita na cena $\theta 1$, a qual desencadeia a cena $\theta 2$.

\section{Cena 1 - Depoimentos sobre a escrita na escola: a tarefa de língua inglesa ${ }^{9}$}

\begin{tabular}{|c|c|c|}
\hline T.01 & Mãe & O que você responderia pra Paula? \\
\hline T.02 & Filha & Hã:::....(+) Na minha tarefa? \\
\hline T.03 & Mãe & Não... o que você responderia DE VERDADE \\
\hline T.04 & Filha & $\begin{array}{l}\text { Hã::....(+) "oi Paula, eu moro no Brasil, POR QUE você me contou todo/toda a } \\
\text { sua ro/rotina... não quero saber da sua vida... POR QUE você me contou que } \\
\text { estudou pro teste de matemática... por que você me contou que você passeia com } \\
\text { seu cachorro e por que você me contou que fez balé.. E POR QUE:.: VOCÊ ME } \\
\text { CONTOU os HORÁRIOS que você fez isso? Eu NÂO QUE:::RO saber... muito } \\
\text { obriga:::da..." }\end{array}$ \\
\hline T.05 & Mãe & $(($ risos $))$ \\
\hline T.06 & Filha & $\begin{array}{l}\text { por que simplesmente não falou... gosto de passear com meu cachorro, fazer balé } \\
\text { e estudar para matemática... e PRONTO! }\end{array}$ \\
\hline T.07 & Mãe & $\begin{array}{l}\text { ((risos)) E DAÍ? você tem uma tarefa pra faze:::r... o seu professor quer que você } \\
\text { responda esse e-mail dela... }\end{array}$ \\
\hline T.08 & Filha & $\begin{array}{l}\text { é... e ele não deixa eu colocar i:::sso... porque acha que é falta de EDUCAÇÃO } \\
\text { colocar isso... }\end{array}$ \\
\hline T.09 & Mãe & ((risos)) e daí, o que que você vai fazer? \\
\hline T.10 & Filha & $\begin{array}{l}\text { SEI LÁ!(+) mas eu responderia ASSIM (+) "POR QUE me contou TO:::DO o } \\
\text { seu cotidiano? }\end{array}$ \\
\hline T.11 & Mãe & e você não quer contar seu cotidiano para ela?/ \\
\hline T.12 & Filha & NÃ:::O... QUE FOI? o que que ela quer saber da minha vida? \\
\hline T.13 & Mãe & $(($ risos $))$ Tá bom $(+)$ \\
\hline
\end{tabular}

Cena 2: Depoimentos sobre a escrita na escola: a carta-convite para um amigo

\begin{tabular}{l|l|l} 
T.14 & Mãe & $\begin{array}{l}\text { Eu vou ajudar você a escrever na sua tarefa aquilo que você acabou de me falar, } \\
\text { tá bom? }\end{array}$ \\
\hline T.15 & Filha & $\begin{array}{l}\text { Mas os professores não deixam a gente escrever aquele tipo de coisa. Uma vez, } \\
\text { tinha um trabalho de fazer uma carta para um amigo, convidando ele, DE } \\
\text { VERDADE, pra ele ir na casa/na sua casa... e daí teve um menino que colocou } \\
\text { "e aí...tu/tudo bem, mano? quer ir na minha... casa se/segunda-feira? ... a gente } \\
\text { vai se divertir PRA VALER... vai ser RADICAL” e daí a professora disse "como } \\
\text { você escreveu uma coisa dessas? ... sua mãe DEIXOU você escrever essas } \\
\text { PALAVRAS?” (+) }\end{array}$ \\
\hline T.16 & Mãe & ele tinha escrito só radica:::1/ \\
\hline T.17 & Filha & e mano::: $(+)$ \\
\hline T.18 & Mãe & só isso mesmo? \\
\hline T.19 & Filha & SÓ::: \\
\hline T.20 & Mãe & e era pra um amigo? \\
\hline T.21 & Filha & era... \\
\hline T.22 & Mãe & Hum... \\
\hline T.23 & Filha & $\begin{array}{l}\text { a professora, Ó... ((faz círculos no ar com os dedos indicadores, apontando para } \\
\text { os seus ouvidos }))\end{array}$
\end{tabular}

\footnotetext{
${ }^{8}$ Não entraremos na discussão da autoria deste texto.

${ }^{9}$ As convenções de transcrição da fala são, em sua maioria, as mesmas da escrita convencional, acrescidas das seguintes convenções: / - truncamento ou interrupção abrupta da fala; ... - pausa de pequena extensão; $(+)$ - pausa breve; $(+++)$ - pausa longa; (...) - suspensão de trecho da transcrição original; ::: - alongamento da vogal; "aaa" - discurso reportado; 'aspas ' - leitura de texto; MAIÚSCULA - alterações de voz com efeito de ênfase; [ ] interrupção de um interlocutor ou falas simultâneas; $((\mathrm{xxx}))$ comentário do analista; (xxx) suposição de fala sem nitidez. Essas convenções foram feitas a partir de Marcuschi (2003) e também se baseiam nas utilizadas em Kleiman (2001) e Kleiman e Matencio (2005).
} 


\begin{tabular}{l|l|l} 
T.24 & Mãe & $\begin{array}{l}((\text { risos })) \text { então tá bom... mas vamos tentar escrever isso... vamos ver se esse seu } \\
\text { professor pensa diferente... tá bom? }\end{array}$ \\
\hline T.25 & Filha & Mas todos os professores pensam igual, mamãe (...)
\end{tabular}

Ao perguntar: (T.01) "O que você responderia para a Paula?" e, na sequência, reelaborar sua pergunta acrescentando a expressão (T.03) "de VERDADE", a mãe sinaliza uma orientação discursiva que propõe aproximar a situação de escrita escolar ao uso real da linguagem. Em outros termos, a mãe propõe que a filha pense como ela agiria caso se tratasse de uma interação real. A resposta da criança a essa pergunta, primeiramente com estranheza: (T.02) "Hã?" e depois com o questionamento (T.02): "Na minha tarefa?", aponta para a hipótese de a aluna não estar acostumada a esse movimento reflexivo, dado que não lhe pareceu familiar pensar na escrita a partir dos parâmetros de usos reais da linguagem. Essa estranheza é indicadora de que o uso da linguagem escrita, para a criança, está associado apenas aos limites de uma tarefa escolar.

Já nos turnos 04 e 06, quando relata o que diria à Paula, caso fosse uma situação de interação "de verdade", a criança demonstra um movimento muito mais seguro de uso da linguagem: (T.04) "POR QUE você me contou todo/toda a sua ro/rotina... não quero saber da sua vida..."; (T.06) "Por que simplesmente não falou: gosto de passear com meu cachorro, fazer balé e estudar para matemática... e PRONTO!". Assim se pronunciando, a criança reivindica a posição de um sujeito que evidencia uma atitude responsiva-ativa diante das palavras da (suposta) interlocutora. A criança demonstra-se à vontade para declarar, inclusive, que o conteúdo da (suposta) enunciação de Paula não lhe interessa (T.04) "eu NÃO QUE:::RO saber... muito obriga:::da...”. Nesse movimento, ao colocar em xeque as palavras alheias, evidente - além do mais - por meio dos reiterados "porquês" (T. 04 e 06), é possível perceber uma orientação discursiva de reação e essas palavras. Desse modo, esses turnos evidenciam que há um sujeito que age sobre a linguagem, que não recebe passivamente as palavras alheias, mas reacentua-as, reavalia-as, ressignifica-as. De outro modo, podemos dizer há um sujeito que se distancia do dito e avalia-o; um sujeito que, ativamente, age com e por meio da língua, enfim, que exerce e deixa entrever sua condição responsivo-ativa da linguagem (BAKHTIN, 2003).

Observamos, como efeito dessa ação na e pela linguagem, que a criança vai encontrando caminhos, construindo parâmetros para agir discursivamente e avaliando os efeitos do seu dizer (T.12) "O que que ela quer saber da minha vi:::da?” mesmo que a situação seja hipotética. Percebemos, assim, que quando tem a possibilidade de direcionar seus enunciados à Paula, a situação comunicativa, ainda que não se proponha a extrapolar os muros da escola, parece oferecer sentidos que carregam maiores condições para que a criança atue como sujeito da linguagem. Isso se explica porque, uma vez que a “[ [...] palavra está sempre carregada de um conteúdo ou de um sentido ideológico ou vivencial” (BAKHTIN/VOLOCHINOV, 2004, p. 95), somente reagimos às palavras que nos despertam ressonâncias ideológicas ou concernentes à vida. Ou seja, nossa ação discursiva está relacionada com nossa reação às palavras alheias; quanto mais ressonantes elas nos parecerem, mais capazes de reagir a elas nós seremos. Saber como agir discursivamente, nesse sentido, é saber orientar a nossa resposta, nossa compreensão responsiva-ativa, em função do outro e da situação comunicativa. E isso só parece ser possível a partir de parâmetros sociais da realidade comunicativa que precisam ser ensinados.

O mesmo não ocorre quando a mãe lembra a criança de que se trata de uma atividade escolar e exige dela que pense sobre sua ação discursiva nesta situação de comunicação: "E DAÍ? Você tem uma tarefa pra faze:::r... (T. 09)/ "E daí, o que que você vai fazer?”. A resposta da criança a essas indagações - (T.10): "SEI LÁ!(+) mas eu responderia ASSIM" - demonstra que a estudante não se sente apta a agir discursivamente no contexto comunicativo em que apenas o professor figura como seu interlocutor. Os indícios anteriores de um sujeito ativo - que se distancia do dito e avalia o que lê, elaborando uma resposta-ativa para a enunciação são agora inexistentes.

Desse modo, embora realize avaliações de seus interlocutores e de sua resposta-ativa, nas situações comunicativas caracterizadas como tarefa escolar, em que apenas o professor figura como seu interlocutor, a criança demonstra não ter parâmetros para agir discursivamente. O único parâmetro para sua ação é o de que sua compreensão responsiva da situação comunicativa é incompatível com a ação discursiva exigida/esperada pela escola, como indica o turno 08: "ele não deixa eu colocar i:::sso... porque acha que é falta de EDUCAÇÃO colocar isso..." e reafirma o turno 24: "todos os professores pensam igual". Assim, a estudante sabe apenas que é falta de educação falar assim, mas encontra-se desorientada para a ação discursiva e, assim, mostra-se imobilizada. 
É relevante perceber que isso acontece, inclusive, quando aparentemente se trabalha a partir dos gêneros no ensino de língua portuguesa. Quando observamos o relato da criança sobre a experiência escolar de um colega ao escrever "uma carta para um amigo convidando ele DE VERDADE, pra ele ir na casa/na sua casa" (cena 2), percebemos a tentativa da escola de realizar um trabalho com a língua materna que supere o falseamento no uso da linguagem, por meio de uma atividade que pretende extrapolar os muros escolares, indo além da mesa do professor. Entrevemos, assim, a tentativa da escola de realizar um trabalho com a linguagem que aborde aspectos relativos aos gêneros. Todavia, quando a criança reporta a resposta de seu colega à situação real de produção proposta pela escola - escrever uma carta [convite] para um amigo - destacando a avaliação negativa da professora em relação ao uso dos termos "mano" e "radical": "como você escreveu uma coisa dessas? ... Sua mãe DEIXOU você escrever essas PALAVRAS?” compreendemos que também não estão sendo oferecidos parâmetros significativos de ação discursiva para a criança.

A resposta da professora à escrita do aluno, relatada pela estudante à sua mãe, demonstra que a situação de comunicação escrita proposta pela escola, embora supostamente real, do mesmo modo que na cena anterior, caracteriza-se novamente como uma tarefa escolar que falseia o uso da linguagem. Nela, a relação entre os sujeitos (crianças), seus papéis sociais (amigos de escola), bem como os objetivos da situação comunicativa (fazer um convite para o amigo ir à sua casa) são completamente ignorados pela escola quando a preocupação demostrada é com relação aos possíveis efeitos da escolha de palavras em função de interlocutores que sequer fazem parte da situação de comunicação, neste caso, a mãe (T.15: "Sua mãe DEIXOU você escrever essas PALAVRAS?”).

Essa preocupação com a avaliação externa - a da mãe que hipoteticamente desaprovaria o uso dos termos "mano" e "radical" - evidencia que a orientação discursiva que a escola dá à atividade de escrita, em vez de direcionar-se em função dos elementos do cenário que compõem a situação comunicativa proposta, projetase para fora dela, num movimento que desconfigura a própria atividade, tirando-lhe seus aspectos enunciativos constitutivos. Assim caracterizado, o trabalho escolar com os gêneros, mesmo que se proponha a extrapolar o circuito aluno-professor, distancia-se do que é fundamental da teoria bakhtiniana dos gêneros: sua dimensão sócio-comunicativa e sua maleabilidade, configurando-se, ainda que com alguns acréscimos, no mesmo tipo de tarefa escolar observado na cena $\theta 1$. Essa constatação se assemelha ao que haviam percebido Martins (2009a) e Rodrigues (2014) em seus trabalhos, conforme já citado.

Tanto a cena $\Theta 1$ quanto a cena $\Theta 2$ evidenciam, assim, que está sendo construída pela criança, por meio da escola, a representação dicotômica de que uma coisa é usar a linguagem (oral ou escrita) na escola e outra fora dela, como é especialmente representativo o turno 15: "Mas os professores não deixam a gente escrever aquele tipo de coisa". Assim vista, a linguagem verbal sofre uma abstração mutiladora, que é a de se circunscrever, única e exclusivamente, ao caráter de uma tarefa escolar.

Como vimos, a partir da perspectiva do dialogismo bakhtiniano, a produção da linguagem, assim como a constituição dos sujeitos, só é possível a partir das interações verbais. O uso da palavra, no prisma bakhtiniano, "[...] é sempre determinada tanto pelo fato de que procede de alguém, como pelo fato que se dirige a alguém". (BAKHTIN/VOLOCHINOV, 2004, p. 113). Por assim se caracterizar, a expressão verbal humana é resultado da sua relação com o outro, e essa relação está circunscrita às situações comunicativas reais.

Ao favorecer a construção de uma representação falseada do uso da escrita, a escola desconsidera a natureza dialógica da linguagem, tirando-lhe o que há na língua de essencial: sua natureza social. Com isso, a escola materializa as prospectivas negativas apontadas por Bunzen (2004). O autor já nos advertira de que o ensino de língua corria o sério risco de, mesmo trabalhando com gêneros, continuar sendo orientado por uma " [...] visão de língua homogênea e estereotipada, priorizando os aspectos mais formais e desprezando os elementos pragmáticos e discursivos" (BUNZEN, 2004, paginação irregular).

Como consequência maior dessa falsa representação da língua, de acordo com os dados observados, parece haver uma interdição do sujeito, que passa a não saber como agir discursivamente em dada situação comunicativa, assim como já havia observado Kleiman (2007). Quando se desvincula a produção verbal da realidade social, dos usos reais da linguagem, limita-se a possibilidade de ação do sujeito, uma vez que, mesmo imbuído de resposta (inerentemente intrínseca à linguagem), ele não tem parâmetros para orientá-la discursivamente quando a situação de uso da linguagem escrita é falseada e o único interlocutor é o professor. 
Todavia, cumpre-nos lembrar que a escola é, também, um construto social, afetado histórica e discursivamente pelos sujeitos que nela e com ela convivem. E, no caso em análise, estamos nos referindo especificamente a uma escola da rede particular de ensino que tem suas especificidades próprias de trabalho. Tal contexto pode justificar, de certo modo, as ações que se fazem com a linguagem em situação de ensino que, muitas vezes, por exigências externas (dos pais) e internas (da política da instituição) delimita o que pode (ou não) ser dito ou trabalhado no ensino. Não podemos afirmar categoricamente que o posicionamento do professor represente seu modo de compreender a linguagem e o trabalho com os gêneros na escola, já que se trata também de um sujeito que age em determinado contex to que lhe confere modos de agir e de dizer dentro dos parâmetros que lhe foram estabelecidos.

\section{APONTAMENTOS FINAIS}

Neste trabalho partimos do princípio de que o adentramento do viés enunciativo-discursivo da linguagem nos campos da pesquisa e do ensino, decorrente especialmente da publicação dos Parâmetros Curriculares Nacionais na década de 1990, trouxe contribuições significativas ao ensino de língua portuguesa sobretudo porque traz a possibilidade de consideração da relação entre a língua e a sociedade a partir dos usos reais da linguagem. Se consideramos que só há sujeitos na ação via linguagem, na inter-relação com o outro, um ensino de línguas que não desconsidere seu caráter dialógico dará mais condições para que os alunos aprendam como agir discursivamente de forma mais autônoma.

O trabalho com os gêneros se mostra relevante para este intuito, dado que eles carregam as marcas das esferas de atividades humanas em que são produzidos. Sendo assim, eles fornecem elementos essenciais para a ação discursiva, podendo oferecer parâmetros para que o sujeito oriente sua ação por meio da linguagem.

Como vimos, alguns autores têm apontado que, embora a teoria dos gêneros tenha adentrado tanto a escola quanto as pesquisas acadêmicas, nem em um caso nem em outro, isso têm significado reinterpretações que mantêm coerência com a perspectiva inicialmente proposta pelo Círculo de Bakhtin (cf. RODRIGUES, 2004). Conforme apontamos, uma das consequências desse distanciamento da perspectiva bakhtiniana, no caso do ensino escolar, tem sido que a concepção de língua que prioriza os aspectos formais em detrimento de elementos sócio-discursivos ainda se mostra presente na escola, não dando espaço para que o aluno atue, nas produções escolares, como sujeito da linguagem que naturalmente ele é.

Para superar essa concepção de linguagem potencialmente limitadora, este trabalho aponta a necessidade de que a escola faça mais do que solicitar textos com nomes pré-definidos ou propor que os textos tenham outros interlocutores além do professor. Parece ser necessário, primeiramente, que ela dê espaço para que o aluno atue como sujeito da linguagem; que dialogue com a palavra alheia expressa por meio dos textos; que as refute, que as assimile, que as reelabore, que as reacentue, etc., enfim, que lide com a palavra alheia de modo ativo e responsivo. Além disso, se faz necessário que a escola oriente a ação discursiva do aluno oferecendo parâmetros pautados em situações comunicativas concretas e a partir dos elementos sócio-históricos e culturais que as constituem.

Por fim, cabe a importante ressalva, feita por Martins (2009a), a respeito das reinterpretações pelas quais passou a teoria bakhtiniana. Essas ressignificações são apontadas pela autora como marca do contato da teoria tanto com práticas pedagógicas bastante tradicionais, quanto pela própria reinterpretação dada pelas instâncias administrativas, via documentos paramétricos, por exemplo. O resultado disso, de acordo a mesma autora, é uma bricolagem que corre o risco de desvincular o trabalho com os gêneros dos princípios a eles inerentes, ou seja, com a própria teoria dialógica. Sendo assim, cumpre destacar, além do mais, que o professor não pode ser o único a ser responsabilizado por essa possível desvinculação, dado que a formação docente têm se mostrado ineficiente para reorientar as concepções que os professores trazem de suas experiências escolares (TARDIF, 2002), bem como as instâncias administrativas pouco têm contribuído para a ressignificação das práticas docentes (cf. KLEIMAN; MARTINS, 2007). 


\section{REFERÊNCIAS}

ACOSTA-PEREIRA, R.; RODRIGUES, R. H. Perspectivas atuais sobre gêneros do discurso no campo da Linguística. Letra Magna, Revista Eletrônica de Divulgação Científica em Língua Portuguesa, Linguística e Literatura, ano 05, n.11, p. 1-18, $2^{\circ}$ semestre de 2009.

ANDRÉ, M. E. D. A. Estudo de Caso em Pesquisa e avaliação educacional. Brasília: Liber Livro Editora, 2005.

BAKHTIN, M. Estética da criação verbal. 4. ed. São Paulo: Martins Fontes, 2003.

O discurso no romance. In: Questões de Literatura e Estética. São Paulo: Hucitec, 1988.

; VOLOCHINOV, V. Marxismo e Filosofia da Linguagem. 11. ed. Hucitec: São Paulo, 2004.

BRAIT, B. A natureza dialógica da linguagem: forma e graus de representação dessa dimensão constitutiva. In: FARACO, C. A.; TEZZA, C.; CASTRO, G. de (Org.). Diálogos com Bakhtin. 4. ed. Curitiba: Editora UFPR, 2007.

BRASIL, Secretaria da Educação Fundamental. Parâmetros Curriculares Nacionais: língua portuguesa. Brasília, DF: Secretaria de Educação Fundamental, 1997.

BORTONI-RICARDO, S. M. O professor pesquisador: introdução à pesquisa qualitativa. São Paulo: Parábola Editorial, 2008.

BUNZEN, C. O ensino de gêneros em três tradições: implicações para o ensino-aprendizagem de língua materna. $2004 . \quad$ Disponível em: <http://www.letramento.iel.unicamp.br/publicacoes/artigos/o_ensino_de_generos_ClecioBunzen.pdf>. Acesso em: 12 dez. 2013.

DENZIN, Norman. K. e LINCOLN, Yvonna. S. Introdução: a disciplina e a prática da pesquisa qualitativa. In:_ (Org.). O Planejamento da pesquisa qualitativa: teorias e abordagens. Porto Alegre: Artmed, 2006. p.15-41.

ERICKSON, F. Métodos cualitativos de investigación. In: WITTROCK, M. La investigación de la ensenanza, II. Barcelona- Buenos Aires-Mexico: Paidos, 1989, p. 195-299.

FIORIN, J.L. Introdução pensamento de Bakhtin. São Paulo: Ática, 2008.

GERALDI, J. W. Portos de passagem. São Paulo: Martins Fontes, 1997.

KLEIMAN, A. B. Letramento e suas implicações para o ensino de língua materna. Signo (UNISC. Online), v. $32, \quad \mathrm{n} \quad 53, \quad$ p. $\quad 1-25, \quad 2007.20$ Disponível http://online.unisc.br/seer/index.php/signo/article/viewFile/242/196 Acesso em 20 jul.2011.

KLEIMAN, A.; MARTINS, M. S. C. Formação de professores: a contribuição das instâncias administrativas na conservação e na transformação de práticas docentes. In: KLEIMAN, A. B; CAVALCANTI, M. (Org.). Linguística Aplicada: suas faces e interfaces. Campinas, SP: Mercado de Letras, 2007. p. 273-298.

LUNARDELLI, M. G. Um haicai para o estágio, um estágio para o haicai: diálogos sobre o gênero discursivo e a formação docente inicial. 2012. 338 f. Tese (Doutorado em Estudos da Linguagem) - Universidade Estadual de Londrina, Londrina.

MARTINS, M. S. C. Avanços e retrocessos nas propostas para o ensino da língua portuguesa: a didatização dos gêneros do discursos. In: SIGET - SIMPÓSIO INTERNACIONAL DE ESTUDOS DE GÊNEROS TEXTUAIS, 5.; 2009, Caxias do Sul-RS. Anais... Caxias do Sul-RS: UCS, 2009. Disponível em http://www.ucs.br/ucs/tplSiget/extensao/agenda/eventos/vsiget/portugues/anais/textos_autor/arquiv 
os/avancos_e_retrocessos_nas_propostas_para_o_ensino_da_lingua_portuguesa_a_didatizacao.pdf Acesso em 02 dez. 2013.

MARTins, M. S. C. Os gêneros do discurso e o ensino de língua portuguesa. 2009b. Disponível em http://www.iel.unicamp.br/letramento/publicacoes/artigos/Generos_do_discurso_ensino.pdf Acesso em O2 dez. 2013.

MATENCIO, Maria de Lourdes Meirelles. Referenciação e retextualização de textos acadêmicos: um estudo do resumo e da resenha. CONGRESSO INTERNACIONAL DA ABRALIN, III.; 2003. Rio de Janeiro. Anais.... Rio de Janeiro: UFRJ. 2003. p. 110-120.

MOITA LOPES, L. P. Linguística aplicada: contexto e a metodologia de pesquisa "territorio do onde estou eu, pesquisadora, também uma outra? In: Parábola Editorial, 2006. p.237- 279. Por uma Linguística Aplicada indisciplinar. São Paulo:

PERFEITO, A. M. Concepções de linguagem, teorias subjacentes e ensino de língua portuguesa. In: SANTOS, A. R.; RITTER, L.C. (Org.s.) Concepções de linguagem e ensino de língua portuguesa. (Formação de Professores EAD 18), v. 1. Maringá: EDUEM, 2005.p.27-79.

RODRIGUES, R. H. Os gêneros do discurso nas aulas de Língua Portuguesa: (re)discutindo o tema. In: NASCIMENTO, E. L. do; ROJO, R. (Org.) Gêneros de texto/discurso: e os desafios da contemporaneidade. Campinas, SP: Pontes Editores, 2014.p.35-54.

. A pesquisa com os gêneros do discurso na sala de aula: resultados iniciais. In: CELLI - COLÓQUIO DE ESTUDOS LINGUÍSTICOS E LITERÁRIOS, 3.; 2007, Maringá-PR. Anais... Maringá: UEM, 2009. p. 2010-2019. Disponível em: <http://periodicos.uem.br/ojs/index.php/ActaSciLangCult/article/view/6004/6004>. . Acesso em 03 dez. 2013.

- Análise de gêneros do discurso na teoria bakhtiniana: algumas questões teóricas e metodológicas. Lingugem em (Dis)curso, Tubarão, v. 4, n. 2, p. 415-440, jan/jun. 2004.

. A constituição e funcionamento do gênero jornalístico artigo: cronotopo e dialogismo. $2001.347 \mathrm{f}$. Tese (Doutorado em Linguística Aplicada e Estudos da Linguagem) - Pontifica Universidade Católica de São Paulo, São Paulo.

ROJO, R. Gêneros do discurso e gêneros textuais: questões teóricas e aplicadas. In: MEURER, J. L.; BONINI, A.; MOTTA-ROTH, D. (Org.). Gêneros: teorias, métodos, debates. São Paulo: Parábola, 2005. p. $184-207$.

TRAVAGLIA, L. C. Gramática e interação: uma proposta para o ensino de gramática no $1^{\circ}$ e $2^{\circ}$ graus. São Paulo: Cortez, 1996.

TARDIF, M. Saberes docentes e formação profissional. Petrópolis, RJ: Vozes, 2002.

Recebido em 02/04/2015. Aprovado em 30/05/15. 